\title{
Trends of Follow-Up Clinic Visits and Admissions Three-Months Before and During COVID-19 Pandemic at Tikur Anbessa Specialized Hospital, Ethiopia: an Interrupted Time Series Analysis
}

Workeabeba Abebe ( $\nabla$ workeabebasol@gmail.com )

Addis Ababa University

Alemayehu Worku

Addis Ababa University

Tamirat Moges

Addis Ababa University

Nuhamin Tekle

Addis Ababa University

Wondowossen Amogne

Addis Ababa University

Tewodros Haile

Addis Ababa University

Desalew Mekonen

Addis Ababa University

Abebe Habtamu

Addis Ababa University

Wakgari Deressa

Addis Ababa University

Research Article

Keywords: Admission, COVID-19, Ethiopia, Follow-up visit, Health-care utilization, TASH, Trends.

Posted Date: January 13th, 2021

DOl: https://doi.org/10.21203/rs.3.rs-135977/v1

License: (1) This work is licensed under a Creative Commons Attribution 4.0 International License.

Read Full License 
Version of Record: A version of this preprint was published at BMC Health Services Research on July 23rd, 2021. See the published version at https://doi.org/10.1186/s12913-021-06730-8. 
4 Workeabeba Abebe ${ }^{1 *}$, Alemayehu Worku², Tamirat Moges ${ }^{1}$, Nuhamin Tekle ${ }^{3}$, Wondowossen

5 Amogne $^{4}$, Tewodros Haile ${ }^{4}$, Desalew Mekonen ${ }^{4}$, Abebe Habtamu $^{1}$, Wakgari Deressa ${ }^{2}$.

9 1. Department of Pediatrics and Child Health, College of Health Sciences, Addis Ababa University, Addis Ababa, Ethiopia

2. School of Public Health, College of Health Sciences, Addis Ababa University, Addis Ababa, Ethiopia

3. Department of Family Medicine, College of Health Sciences, Addis Ababa University, Addis Ababa, Ethiopia

4. Department of Internal Medicine, College of Health Sciences, Addis Ababa University, Addis Ababa, Ethiopia

23 * Corresponding author: Workeabeba Abebe (WA)

24 E-mail: workeabebasol@gmail.com 


\section{Abstract}

26 Background: Following the first report of the COVID-19 case in Ethiopia on the $13^{\text {th }}$ of

27 March 2020, the country adopted a lockdown policy to contain the spread of the virus.

28 Responding to the health-care burden imposed by the COVID-19 pandemic had to be coupled

29 with ensuring essential health care services. This study assessed the impact of COVID-19 on the

30 trends of non-COVID follow-up visits and admissions at Tikur Anbessa Specialized Hospital,

31 Addis Ababa, Ethiopia.

32 Methods: A retrospective, time-series study with the $1^{\text {st }}$ case of COVID-19 report as a

33 reference time examined the trend in follow-up visits and admissions between December $1^{\text {st }}, 2019$

34 and May $31^{\text {st }}, 2020$. A comparison of health care utilization between December 2019 to May 2020

35 and its equivalent period in 2018/19 was also done. A data abstraction tool was used to collect

36 secondary data from the hospital's electronic medical recordings and logbooks of each unit.

37 Results: A total of 7,717 visits from eight follow-up clinics and 3,310 admissions were

38 collected during three months before the onset of COVID-19. During the following three months

39 after the pandemic, 4,597 visits and 2,383 admissions were collected. Overall, a $40.4 \%$ decrease

40 in follow-up visits and a $28 \%$ decline in admissions were observed during the COVID-19. The

41 drop in the daily follow-up visits was observed for both genders. The number of visits in all

42 follow-up clinics in 2019/2020 decreased when compared to the same months in

$432018 / 19(\mathrm{p}<0.05)$. Follow-up visits were substantially lower for renal patients $(-68 \%)$, patients

44 with neurologic problems $(-53.9 \%)$, antiretroviral treatment clinics $(-52.3 \%)$, cardiac patients

$45(-51.4 \%)$. Although pediatric emergency admission was significantly lower (-54.1\%) from the 
46 baseline $(\mathrm{p}=0.04)$, admissions from the general pediatric and adult wards did not show a

47 significant difference.

48 Conclusions: Significant decreases in-hospital follow-up clinic visits were observed during

49 the first months of the COVID-19 pandemic. Public health guidance on how best to access care,

50 more for patients with serious illnesses are required. Promoting self-care, alternatives health-care

51 services like home-based care, and phone clinics might be considered for patients with mild

52 symptoms. Further studies needed to track the long-term effect of the pandemic among non-

53 COVID-19 patients.

54 Keywords: Admission, COVID-19, Ethiopia, Follow-up visit, Health-care utilization, TASH,

55 Trends.

56

57

58

59

60

61

62

63

64

65

66

67

68 


\section{Background}

70 In Ethiopia, the first case of the novel coronavirus disease 2019 (COVID-19) was reported on $13^{\text {th }}$

71 of March 2020. Ethiopia adopted a lockdown policy to contain the spread of the virus and schools

72 were closed on March 16, 2020 and travel bans were put in place on March 20, 2020.

73 Subsequently stay at home orders were recommended to the public and the country declared a

74 state of emergency on April 8, $2020(1,2)$. Despite efforts to prevent the spread of COVID-19 in

75 Ethiopia, new cases continued to emerge among individuals with travel history and even without

76 clear exposure. The community transmission has been already established and the virus has been

77 distributed to every part of the country. As of November $5^{\text {th }}, 2020$, the total number of confirmed

78 COVID-19 cases in Ethiopia was 98391, of which 1508 died and 57000 recovered (3, 4).

79 Although the virus was detected in all age groups, severe symptoms were reported mainly in older

80 age groups. People with pre-existing medical conditions such as hypertension, diabetes, and heart

81 disease appear to be more vulnerable to becoming severely ill with COVID-19 (5).

82 The COVID-19 pandemic continues to challenge the healthcare systems around the world.

83 Responding to the healthcare burden imposed by the pandemic required intense resources. Even

84 more, this had to be coupled with ensuring essential healthcare services (6). Countries struggled

85 to fairly allocate resources for these needs. Hospitals operated with less capacity due to the

86 distribution of resources for COVID-19 prevention, detection, and case management. Some of the

87 care provided in hospitals such as elective surgery and other non-critical medical services were

88 purposefully curtailed (7). In addition, following the initial public health messaging that

89 discouraged unnecessary healthcare use, many patients delayed or canceled follow-up

90 appointments in hospitals $(8,9)$. The low utilization of emergency services was also evident (10).

91 In Singapore, doctor visits decreased by up to $30 \%$ while a massive drop of $63.8 \%$ in pediatric 
92 emergency health-care utilization was observed in Germany and a comparable 63.5\% reduction in

93 emergency department visits were reported in the U.S. (11-13).

94 The delayed access or provision of care affected both acute and chronic care $(14,15)$, and resulted 95 in increased adverse outcomes from non-COVID-19-related illnesses $(16,17)$. The main reason

96 for the reduced hospital visits was fear of contracting COVID-19 in health-care settings and

97 restricted transports due to social distancing measures $(18,19)$. However, a reduction in some 98 acute infections that have a person-to-person transmission risk and illnesses related to 99 environmental exposure such as allergens and air pollution as well as traumas was also observed 100 in some settings $(14,20)$. Furthermore, the application of telemedicine created alternative access 101 to care; partly explaining the reduced number of in-person care (21).

102 In this study, we assessed the impact of COVID-19 on the trends in hospital visits and admissions 103 at Tikur Anbessa Specialized Hospital (TASH) in Ethiopia. We compared the rate of follow-up 104 clinic visits and admissions for the three months before and after the first report of the COVID-19 105 case in 2020. In addition, we compared the trends in hospital visits from December 2019 to May 1062020 to the equivalent period in the previous year (Dec 2018 to May 2019). 


\section{Methods}

\section{Setting}

118 This study was conducted at TASH located in Addis Ababa, Ethiopia. TASH serves as a public

119 institute training center with about 700 beds. The hospital serves a large population of patients

120 referred for outpatient and inpatient care in all core specialties (internal medicine, emergency,

121 critical care, surgery, pediatrics and obstetrics/gynecology). The hospital also provides specialized

122 and sub-specialized clinical services to the patients referred from other hospitals and health

123 institutions across all parts of the country. Of the total beds, about 150 are medical (including 12

124 intensive care unit [ICU] beds), 172 beds are in pediatrics (including 4 pediatric ICU beds). Both

125 adult and pediatric emergency rooms (ER) are open to patient's 24 hours a day and seven days a

126 week. Clinical care teams composed of nursing staff; medical students and residents supervised

127 by attending staff provide all care for in-patients. TASH started to have functional electronic

128 database recording system for most of the adult clinics since 2018; however, the health records

129 from pediatrics and some clinics from adult side were still paper-based recordings.

\section{Study design and period}

131 A retrospective time series study was conducted to collect daily follow-up visits, and monthly

132 admissions data at TASH between December $1^{\text {st }}, 2019$ and May 31 ${ }^{\text {st }}, 2020$. A before-after study

133 was done to analyze the trend in daily follow-up visits and monthly admissions with the $1^{\text {st }}$ case

134 of COVID-19 report (March $13^{\text {th }} 2020$ ) as a cut of point. We also compared health care utilization,

135 between December 2019 to May 2020 and its equivalent period in 2018/19. A quantitative

136 method using structured data abstraction tools was used to collect the data. Data abstraction was

137 conducted from May to June 30, 2020. 


\section{Data collection and procedures}

139 A study team comprised of clinicians and public health experts developed a data abstraction tool

140 after reviewing the available literature. We collected secondary data during the selected periods

141 from the hospital's Health Management Information System (HMIS) and logbooks in each

142 outpatient clinic, emergency/casualty department, and wards of TASH. A one-day training to data

143 collectors was conducted on the data collection tools and procedures. Trained nurses from each

144 unit collected data that were collected as part of the routine hospital service. Eight outpatient

145 follow-up clinics ( 4 adult and 4 pediatric clinics) were included. These clinics were selected based

146 on the availability of the documentation of the required information. In addition, both adult and

147 pediatric inpatient wards were included. The main outcome variables were daily follow-up visits

148 and monthly hospital admissions of adult and pediatric wards.

\section{Inclusion/Exclusion}

150 Follow-up clinics visits, and admissions, between December $1^{\text {st }}, 2019$, and May $31^{\text {st }}, 2020$ as well

151 as previous year follow-up clinics visits, and admissions between December $1^{\text {st }}, 2018$ and May

$15231^{\text {st }} 2019$ were included in this study. Clinics with incomplete documentation were excluded

\section{Statistical analysis}

154 All data were entered into a password-secured database using Microsoft Excel. After cleaning the

155 data were exported to STATA version 14. We analyzed the trend of daily follow-up visits and 156 monthly hospital admissions. Data were summarized using graphs; mean (standard error of mean

157 [SEM])). Wilcoxon Signed-Ranks test was used to detect mean differences of 2018/19 and 158 2019/20 trend of the follow up visits and ward admission differences. P-value below 0.05 was 159 considered as significant. 


\section{Ethical consideration}

161 The study was granted ethical approval from the Institutional Review Board (IRB) of the College

162 of Health Sciences, Addis Ababa University (Protocol Number:042/20/SPH). Informed

163 consent was waived by the IRB, which approved the study. All personnel involved in this study

164 trained in infection prevention and control procedures (standard contact, droplet or airborne

165 precautions). Data were completely anonymous. All methods were carried out in accordance with

166 relevant guidelines and regulations.

\section{Results}

168 Overall, 12,314 follow-up visits and 5,693 hospital admissions solely non-COVID-19 data were 169 collected. Taking $1^{\text {st }}$ case of COVID-19 report in country as a cut of, 7,717 follow-up visits 170 happened before (3 months) and the rest 4,597 follow-up visits after (3 months). Separately, 1713,310 hospital admissions before ( 3 months) and 2,383 admissions after ( 3 months) of the $1^{\text {st }}$ case 172 of COVID-19 report was collected (Table 1). Similarly, 15, 583 follow-up visits and 6,639 173 hospital admissions solely non-COVID-19 data of last year of the same time also collected. The 174 decrease in follow-up clinic visits and admissions after the onset of COVID-19 was $40.4 \%$ and $17528 \%$, respectively. We observed variations in the number of visits and admissions across the 176 follow-up clinics and inpatient wards. Follow-up visits were substantially lower for renal patients 177 (-68\% below baseline), patients with neurologic problems $(-53.9 \%)$, Anti-retroviral treatment 178 clinics $(-52.3 \%)$, cardiac patient $(-51.4 \% \mathrm{t})$. Although, pediatric emergency admission was 179 significantly lower $(-54.1 \%)$ from the baseline, admissions from the general pediatric $(-14.7 \%)$ 180 and adult (-6.9\%) wards were not that much affected. 
183 percentage reduction, TASH, 2020

\begin{tabular}{|c|c|c|c|c|c|c|c|c|c|}
\hline \multirow[t]{2}{*}{ Characteristics } & \multicolumn{3}{|c|}{ Pre-COVID-19 } & \multirow[t]{2}{*}{ Total } & \multicolumn{3}{|c|}{ During-COVID-19 } & \multirow[t]{2}{*}{ Total } & \multirow{2}{*}{$\begin{array}{l}\text { *Percent } \\
(\%) \\
\text { reduction }\end{array}$} \\
\hline & Dec & Jan & Feb & & Mar & Apr & May & & \\
\hline \multicolumn{10}{|l|}{ Follow-up clinics } \\
\hline Neurology & 599 & 643 & 467 & 1709 & 275 & 265 & 247 & 787 & -53.9 \\
\hline Cardiac & 511 & 618 & 422 & 1551 & 288 & 260 & 206 & 754 & -51.4 \\
\hline Hema. - Oncology & 481 & 525 & 582 & 1588 & 449 & 460 & 465 & 1374 & -13.5 \\
\hline Pediatric - ART & 296 & 337 & 264 & 897 & 127 & 152 & 149 & 428 & -52.3 \\
\hline Endocrine & 251 & 238 & 269 & 758 & 222 & 205 & 139 & 566 & -25.3 \\
\hline HRIC & 226 & 110 & 196 & 532 & 125 & 130 & 133 & 388 & -27.1 \\
\hline Renal & 123 & 128 & 124 & 375 & 38 & 40 & 42 & 120 & -68.0 \\
\hline Gastro-intestinal & 110 & 71 & 126 & 307 & 88 & 58 & 34 & 180 & -41.4 \\
\hline $\begin{array}{l}2019 / 20 \text { (Overall } \\
\text { visit) Total }\end{array}$ & 2597 & 2670 & 2450 & 7717 & 1612 & 1570 & 1415 & 4597 & -40.4 \\
\hline $\begin{array}{l}\text { 2019/20 (Ped. ER } \\
\text { admission) }\end{array}$ & 406 & 421 & 398 & 1225 & 200 & 212 & 150 & 562 & -54.1 \\
\hline $\begin{array}{l}\text { 2019/20 (Ped. Ward } \\
\text { admission) }\end{array}$ & 532 & 535 & 469 & 1536 & 460 & 480 & 370 & 1310 & -14.7 \\
\hline $\begin{array}{l}\text { 2019/20 (Adult ward } \\
\text { admission) }\end{array}$ & 173 & 181 & 195 & 549 & 185 & 164 & 162 & 511 & -6.9 \\
\hline Overall admission & 1111 & 1137 & 1062 & 3310 & 845 & 856 & 682 & 2383 & -28.0 \\
\hline
\end{tabular}

*Percentage Changes in follow-up clinics visits \& admission

In total, 131observation (daily working days hospital follow up visits in six months) occurred at TASH during the analyzed period with 66 before and 65 after first COVID-19 case seen in

188 Ethiopia. We described the daily mean and standard error of mean separately for male and female 189 who visited outpatient clinics three months before and after the first report of COVID-19 case 190 reported in Ethiopia. There were statistically significant declines in the number of daily visits in 191 all follow-up clinics except the Endocrine and GI clinics (Table 2). 
195 of COVID-19, TASH, 2020

\begin{tabular}{|c|c|c|c|c|c|}
\hline \multirow[t]{2}{*}{ Clinics } & \multicolumn{2}{|c|}{$\begin{array}{l}\text { Average daily visits } 3 \text { mon } \\
\text { before } 1^{\text {st }} \text { COVID case }\end{array}$} & \multirow{2}{*}{$\begin{array}{l}\text { Average } \\
\text { 3months } \\
\text { Daily } \\
( \pm \text { SEM) }\end{array}$} & \multirow{2}{*}{\begin{tabular}{cl}
$\begin{array}{r}\text { daily } \\
\text { after } 1^{\text {st }}\end{array}$ & \multicolumn{1}{c}{ visits } \\
COVID \\
mean & $95 \%$ \\
& CI
\end{tabular}} & \multirow[t]{2}{*}{$P$-value } \\
\hline & $\begin{array}{l}\text { Daily mean } \\
( \pm \text { SEM })\end{array}$ & $95 \% \mathrm{CI}$ & & & \\
\hline \multicolumn{6}{|c|}{ *ART clinic } \\
\hline Male & $13.8(0.7)$ & $12.3-15.2$ & $12.2(0.8)$ & $10.5-13.8$ & 0.07 \\
\hline Female & $23.6(1.0)$ & $21.5-25.6$ & $19.7(1.3)$ & $17.1-22.3$ & 0.01 \\
\hline \multicolumn{6}{|c|}{ Cardiac clinic } \\
\hline Male & $24.5(2.4)$ & $19.8-29.3$ & $11.8(1.7)$ & $8.3-15.2$ & 0.00 \\
\hline Female & $37.2(3.6)$ & $30.0-44.6$ & $17.1(2.4)$ & $12.3-21.8$ & 0.00 \\
\hline \multicolumn{6}{|c|}{ Chest clinic } \\
\hline Male & $13.2(1.5)$ & $10.1-16.2$ & $7.0(1.0)$ & $5.0-9.0$ & 0.00 \\
\hline Female & $12.8(1.6)$ & $9.6-15.9$ & $8.5(1.3)$ & $6.0-11.0$ & 0.02 \\
\hline \multicolumn{6}{|c|}{ Endocrine clinic } \\
\hline Male & $19.0(3.1)$ & $12.7-25.3$ & $15.1(2.5)$ & $9.9-20.1$ & 0.16 \\
\hline Female & $23.9(3.9)$ & $16.0-31.7$ & $17.5(2.9)$ & $11.6-23.4$ & 0.09 \\
\hline \multicolumn{6}{|l|}{ \# GI clinic } \\
\hline Male & $2.0(0.4)$ & $1.3-2.8$ & $1.5(0.3)$ & $0.8-2.1$ & 0.13 \\
\hline Female & $1.2(0.2)$ & $0.8-1.7$ & $0.7(0.2)$ & $0.4-1.1$ & 0.05 \\
\hline \multicolumn{6}{|c|}{ \$ HRIC clinic } \\
\hline Male & $3.3(0.2)$ & $2.9-3.8$ & $2.0(0.2)$ & $1.7-2.3$ & 0.00 \\
\hline Female & $2.8(0.2)$ & $2.3-3.2$ & $1.9(0.2)$ & $1.6-2.4$ & 0.00 \\
\hline \multicolumn{6}{|c|}{ Neurology clinic } \\
\hline Male & $18.7(1.0)$ & $16.7-20.7$ & $10.7(0.7)$ & $9.3-12.1$ & 0.00 \\
\hline Female & $11.8(0.7)$ & $10.5-13.2$ & $6.2(0.4)$ & $5.3-7.0$ & 0.00 \\
\hline
\end{tabular}

*ART=Anti Retroviral Treatment, \#GI=Gastro-Intestinal, \$HRIC=High Risk Infant Clinic

198 The trend for six-month daily attendance by male and female patients from two follow-up clinics

199 (Cardiac and ART) at TASH is illustrated in (Fig 1). The clinics were selected since these clinics

200 had daily follow-up throughout the week over the observation period. There was a sharp drop in

201 the daily hospital visits for both genders after mid-March, when the first COVID-19 case was

202 reported. Hospital visit did not rebound to the baseline observation period by the end of May 2032020. 


\section{December 2019 to May 2020}

207 Figure 2 shows the total number of follow-up visits and admissions for six months of Dec 2019-

208 May 2020 compared with the same period of last year (2018/19). The number of visits at the

209 follow up clinics decreased when compared to the same time period in 2018/19. Ward admissions

210 at TASH decreased after the month of February, however the trend is not similar with the follow-

211 up clinics.

Figure 2. Trends in the number of daily follow-up visits from selected clinics by gender from

215 Figure 3 depicted follow up clinics visits separately. In 2019/20, the number of visits at the

216 follow up clinics decreased when compared to the same time period in $2018 / 19$. The relative 217 reduction in monthly follow-up visits was observed in all clinics, except endocrine and 218 hematology- oncology clinics.

Figure 3: Monthly follow-up visits, December 2019 to May 2020 relative to equivalent period in 2018/19.

222 The trend of admissions in the pediatric emergency between December 1st, 2019, and May 31st,

2232020 is illustrated in Figure 4. The monthly report of the number of children who were admitted

224 to the pediatrics Emergency room (ER) showed a significant drop in the month of March and 225 there was no rebound in the month of May $(\mathbf{p}=\mathbf{0 . 0 4})$. 
228 in 2018/19.

229 Figure 5a and 5b illustrate the monthly pediatrics and adult ward admissions and deaths 230 respectively. Pediatrics ward admissions at TASH decreased since the month of February, with 231 the highest drop observed in the month of May 2020. However the difference was not statistically 232 significant $(\mathbf{p}=\mathbf{0 . 3 4})$. Adult medical admissions did not show any difference in 2020 compared to 233 the previous year $(\mathbf{P}=\mathbf{0 . 1 2})$. relative to equivalent period in $2018 / 19$.

\section{Discussion}

239 This study demonstrated a significant decrease in follow-up clinics visits and emergency 240 admissions during the first three months of the COVID-19 pandemic in a tertiary care center in

241 Ethiopia. Furthermore, the case numbers in follow-up clinics during the observed period 242 decreased when compared to the same time in $2018 / 19$. However, the number of children who 243 were admitted to the pediatrics and adult wards didn't show significant difference in the months 244 following March.

245 The decline in the number of overall visits was consistent with the reports from a study in the

246 U.S. where a decline of 0.7 million non- COVID admissions in April 2020 compared to April 2472019 was demonstrated in hospitals across the nation (20). The decline in non-COVID admissions 248 ranged from $39.5 \%$ to $50 \%$ in the minimally affected to greatly affected regions respectively. 
249 Similar studies revealed that the decrease was observed in both primary health care and 250 emergency department visits $(17,22)$. Moreover, these findings were true for pediatric and adult 251 populations across specialty clinics (23-25).

252 Ethiopia, compared to other countries that had significant surge of COVID-19 cases in the first 253 months of 2020, reported fewer cases. However, as a measure of prevention of the spread of the

254 COVID-19 virus in the hospital and effective case management, hospitals were designated as 255 COVID-19 and non-COVID-19 case management centers. TASH was among the designated non256 COVID-19 case management centers, patients who were suspected to have COVID-19, were 257 isolated in a ward and those whose tests confirmed the diagnosis of COVID-19 were transferred 258 out to COVID-19 centers. However, considering the overcrowding and the limited use of personal 259 protective equipment at TASH the anxiety associated with being at an increased risk in this 260 setting was understandable. The fear of contracting COVID-19 in the health-care settings was the 261 commonest explanation for the drop in hospital visits $(7,13)$. Moreover, the testing capacity at 262 institutions and in the country at large was poor to support prevention of transmission. The 263 communication of alarming medical information to the public and the announcement of stay at 264 home order, have also impacted health care seeking behavior.

265 Being a referral hospital, it was believed that patients who were on follow-up and those visiting 266 the emergency department of TASH often have a real need that requires hospital management. In 267 such situations, people opted for a conservative, 'watch and wait' approach (7) while some might

268 have resorted to traditional medicine, as it is a common cultural alternative in Ethiopia. The delay 269 in seeking appropriate health care will have deleterious health outcomes (12). Few outpatient 270 departments had phone clinics that provided an alternative for accessing health care. A 271 compelling contrary argument for the decreased hospital visit was a reduced incidence of illnesses 
272 such as community-acquired pneumonia, which was a reason for most of the pediatric ED visits

273 and in adult patients with co-morbidities $(13,23)$.

274 Looking at the number of children who were admitted to the pediatrics and adult wards showed

275 overall decline -28 , which is lower with the report from U.S where all medical admissions in

276 April declined by 34.1 percent (95\% CI: -34.6, -33.6) (20). We can still consider the drop in

277 admission is significant since TASH is a big hospital/ward where usually all beds were occupied.

278 The impact of COVID-19 on health care resource is huge in the world and more so in low-income

279 countries. Ethiopia being among the low-income countries struggles to adequately allocate human

280 resource, support community-based testing capacity, and provide equipment needed to manage

281 COVID- 19 cases. It is wise to consider that the attempt to respond to the COVID-19 pandemic

282 has compromised the attention given for non-COVID illnesses, which might be a reason for 283 admission declines to reserve beds for possible anticipated surge (13).

\section{$284 \quad$ Limitations}

285 We abstracted a secondary data, and the data were not crosschecked. We took data from the 286 clinics not from individuals therefore we did not do subgroup analysis except by sex. The data in 287 the hospital was not collected for scientific purposes and poor documentation was the reality in 288 our setting so there may be cases that were not documented (missed). TASH is a referral center, 289 and the service was structured according to sub-specialty/specialty clinics so these findings might 290 not be generalized to primary health care and other health care systems.

\section{Conclusion}

292 A significant decrease in follow-up clinics visit and emergency admissions was observed during

293 the first months of the COVID-19 pandemic. Appropriate public health guidance on how best to 294 access care emphasizing on the importance of continuing to visit the health-care facilities for 
295 serious illnesses is required. Promoting of self-care, implementing of home care and

296 strengthening of phone clinics might be considered for patient with mild symptoms. Further

297 studies needed to track the long-term effect of the pandemic among non-COVID-19 patients.

298 Declarations

299 Consent for publication

$300 \quad$ Not applicable

301 Availability of data and material: The datasets used and/or analyzed during the current study

302 are available from the corresponding author on reasonable request.

303 Competing interests: We declare that we have no competing interest

$304 \quad$ Funding

305 Addis Ababa University (AAU) funded this study.

306 Author Contributions

307 WA, AW, W. Amogne and WD conceived and designed the study. WA, TM, TH, DM and AH

308 supervised data collection. WA and NT prepared the final dataset for analysis. WA and AW

309 analyzed and interpreted the data. WA and NT drafted the manuscript. WD, AW and TM

310 provided major roles in revising the manuscript. All authors read and approved the final

311 manuscript.

312 Acknowledgments

313 The authors are grateful to the research staff at the College of Health Sciences. The authors would

314 also like to thank the data collectors and study participants for their time and contributing to the

315 research. 


\section{References}

318 1. Ethiopian Public Health Institute. National Public Health Emergency Operation Center.

319 COVID-19 Pandemic Preparedness and Response. Bulletin No. 1, May 03, 2020. Addis

$320 \quad$ Ababa, Ethiopia.

321 2. Ethiopian Public Health Institute. National Public Health Emergency Operation Center.

322 COVID-19 Pandemic Preparedness and Response. Bulletin No. 7, June 15, 2020. Addis

323 Ababa, Ethiopia.

324 3. Ethiopian Public Health Institute. National Public Health Emergency Operation Center.

325 COVID-19 Pandemic Preparedness and Response. Bulletin No. 26, October 26, 2020. Addis

326 Ababa, Ethiopia.

327 4. Ethiopian Public Health Institute. National Public Health Emergency Operation Center. 328 COVID-19 Pandemic Preparedness and Response. Bulletin No. 27, Nov 5, 2020. Addis 329 Ababa, Ethiopia.

330 5. World Health Organization. Coronavirus Diseases (COVID-19) Situation Reports-World, $331 \quad$ October 2020

332 6. Taquechel K, Diwadkar AR, Sayed S, Dudley JW, Grundmeier RW, Kenyon CC, et al. 333 Pediatric Asthma Health Care Utilization, Viral Testing, and Air Pollution Changes During 334 the COVID-19 Pandemic. J Allergy Clin Immunol Pract. 2020; 8(10):3378-3387.e11. Doi: $335 \quad$ 10.1016/j.jaip.2020.07.057.

336 7. Dopfer C, Wetzke M, Scharff AZ, Mueller F, Dressler F, Baumann U, et al. COVID-19 337 related reduction in pediatric emergency healthcare utilization-a concerning trend. BMC 338 Pediatrics. 2020 Dec; 20(1):1-0. https://doi.org/10.1186/s12887-020-02303-6 
339 8. Emanuel EJ, Persad G, Upshur R, Thome B, Parker M, Glickman A, et al. Fair allocation of 340 scarce medical resources in the time of Covid-19. N Engl J Med 2020; 382:2049-2055. DOI: $341 \quad$ 10.1056/NEJMsb2005114

342 9. Kraemer MU, Yang CH, Gutierrez B, Wu CH, Klein B, Pigott DM, et al. The effect of human 343 mobility and control measures on the COVID-19 epidemic in China. Science. Science 2020 $344 \quad$ May $1 ; 368(6490): 493-7$.

$345 \quad$ DOI: $10.1126 /$ science.abb4218

346 10. Wamsley CE, Kramer A, Kenkel JM, Amirlak B. Trends and challenges of telehealth in an 347 academic institution: the unforeseen benefits of the COVID-19 global pandemic. Aesthetic 348 Surgery Journal. 2020 Jul 22. https://doi.org/10.1093/asj/sjaa212

349 11. Ahn, SangNam and Kim, Seonghoon and Koh, Kanghyock, Changes in Healthcare 350 Utilization, Spending, and Perceived Health during COVID-19: A Longitudinal Study from Singapore (August 2020). Available at SSRN: https://ssrn.com/abstract=3669090 or http://dx.doi.org/10.2139/ssrn.3669090

353

12. Lazzerini M, Barbi E, Apicella A, Marchetti F, Cardinale F, Trobia G. Delayed access or provision of care in Italy resulting from fear of COVID-19. Lancet Child Adolesc Health. 2020 May 1;4(5):e10-1DOi:https://doi.org/10.1016/S2352-4642(20)30108-5

13. Jeffery MM, D’Onofrio G, Paek H, Platts-Mills TF, Soares WE, Hoppe JA, et al. Trends in emergency department visits and hospital admissions in health care systems in 5 states in the first months of the COVID-19 pandemic in the US. JAMA Intern Med. 2020;180(10):13281333. doi:10.1001/jamainternmed.2020.3288

14. Elmore JG, Wang PC, Kerr KF, Schriger DL, Morrison DE, Brookmeyer R, et al. Excess Patient Visits for Cough and Pulmonary Disease at a Large US Health System in the Months 
364 15. Marijon E, Karam N, Jost D, Perrot D, Frattini B, Derkenne C, et al. Out-of-hospital cardiac 365 arrest during the COVID-19 pandemic in Paris, France: a population-based, observational 366 study. Lancet Public Health. 2020 May 27. https://doi.org/10.1016/S2468-2667(20)30117-1

367 16. Lynn RM, Avis JL, Lenton S, Amin-Chowdhury Z, Ladhani SN. Delayed access to care and 368 late presentations in children during the COVID-19 pandemic: a snapshot survey of 4075 369 paediatricians in the UK and Ireland. Archives of Disease in Childhood. 2020 Jun 24. $370 \quad$ http://dx.doi.org/10.1136/archdischild-2020-319848

371 17. Tam CC, Cheung KS, Lam S, Wong A, Yung A, Sze M, et al. Impact of coronavirus disease 372 (COVID-19) outbreak on ST-segment-elevation myocardial infarction care in Hong 373 Kong, China. Circ Cardiovasc Qual Outcomes. 2020 Apr;13(4):e006631. 374 https://doi.org/10.1161/CIRCOUTCOMES.120.006631

375 18. Khairat S, Meng C, Xu Y, Edson B, Gianforcaro R. Interpreting COVID-19 and virtual care 376 trends: cohort study. JMIR Public Health Surveill 2020;6(2):e18811 doi:10.2196/18811

377 19. Lazzerini M, Barbi E, Apicella A, Marchetti F, Cardinale F, Trobia G. Delayed access or 378 provision of care in Italy resulting from fear of COVID-19. Lancet Child Adolesc Health. 379 2020 May 1;4(5):e10-DOI:https://doi.org/10.1016/S2352-4642(20)30108-5

380 20. Birkmeyer JD, Barnato A, Birkmeyer N, Bessler R, Skinner J. The Impact Of The COVID-19 381 Pandemic On Hospital Admissions In The United States: Study examines trends in US 382 hospital admissions during the COVID-19 pandemic. Health Affairs. 2020 Nov 1:10-377. 383 https://doi.org/10.1377/hlthaff.2020.00980

384 21. Mulholland RH, Wood R, Stagg HR, Fischbacher C, Villacampa J, Simpson CR, et al. Impact 385 of COVID-19 on accident and emergency attendances and emergency and planned hospital 
386 admissions in Scotland: an interrupted time-series analysis. J RSocMed. 2020 Oct $387 \quad$ 4:0141076820962447. https://doi.org/10.1177/0141076820962447

388 22. Feral-Pierssens AL, Claret PG, Chouihed T. Collateral damage of the COVID-19 outbreak:

389 expression of concern. Eur J Emerg Med 2020;27(4):233. Eur J Emerg $390 \quad$ Med10.1097/MEJ.0000000000000717

391 23. Chaiyachati BH, Agawu A, Zorc JJ, Balamuth F. Trends in Pediatric Emergency Department 392 Utilization after Institution of Coronavirus Disease-19 Mandatory Social Distancing. J Pediat. $393 \quad 2020$ Jul 20. doi: 10.1016/j.jpeds.2020.07.048

394 24. Gonçalves-Pinho M, Mota P, Ribeiro J, Macedo S, Freitas A. The Impact of COVID-19 395 Pandemic on Psychiatric Emergency Department Visits-A Descriptive Study. Psychiatric 396 Quarterly. 2020 Aug 25:1-1. https://doi.org/10.1007/s11126-020-09837-z

397 25. Kenyon CC, Hill DA, Henrickson SE, Bryant-Stephens TC, Zorc JJ. Initial effects of the 398 COVID-19 pandemic on pediatric asthma emergency department utilization. JAllergy Clin 399 ImmunolPract. 2020 Sep 1;8(8): 2774-6. https://doi.org/10.1016/j.jaip.2020.05.045

400 


\section{Figures}

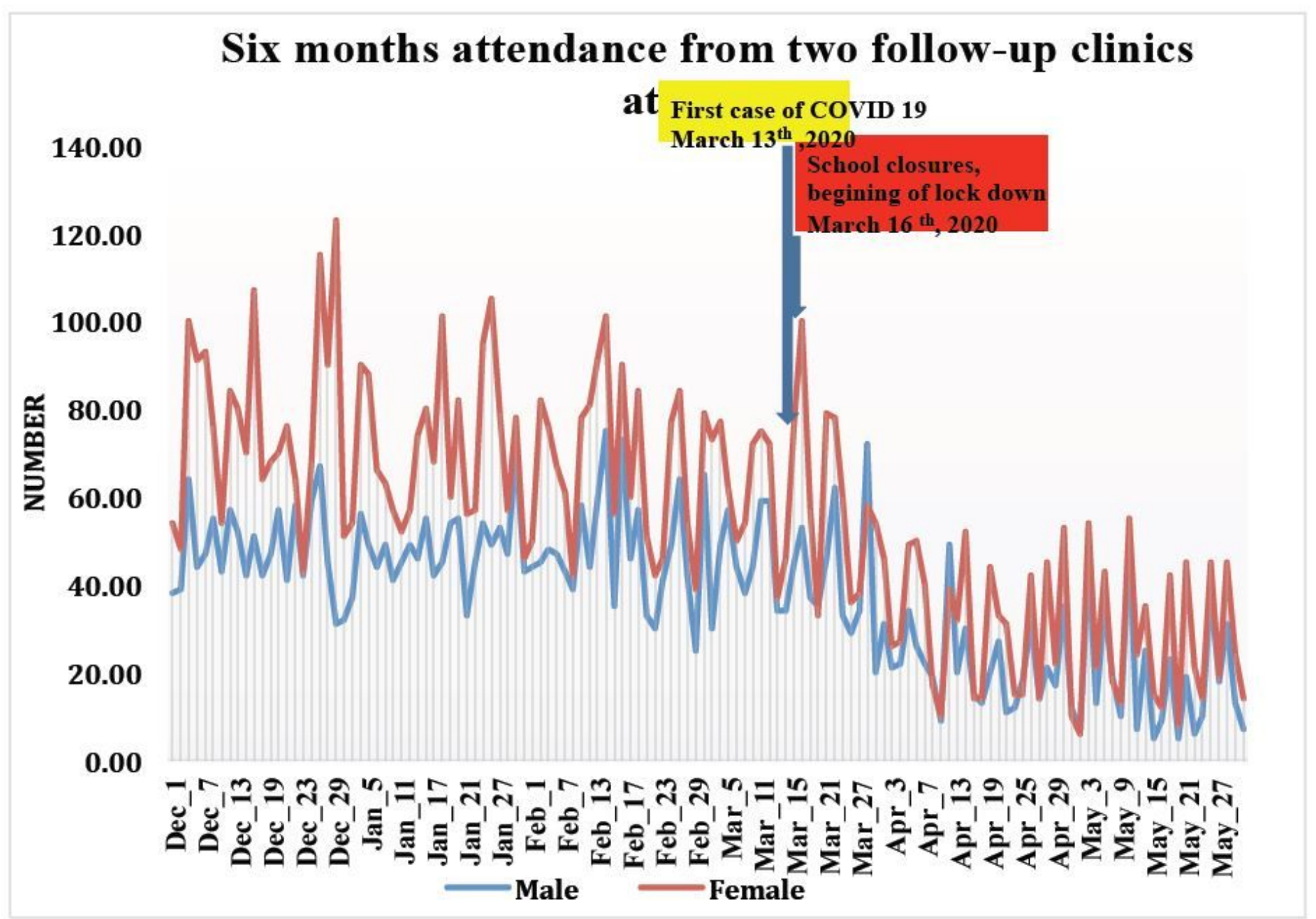

Figure 1

Trends in the number of daily follow-up visits from selected clinics by gender from December 2019 to May 2020 Figure 2 shows the total number of follow-up visits and admissions for six months of Dec 2019- May 2020 compared with the same period of last year (2018/19). The number of visits at the follow up clinics decreased when compared to the same time period in 2018/19. Ward admissions at TASH decreased after the month of February, however the trend is not similar with the follow up clinics. 


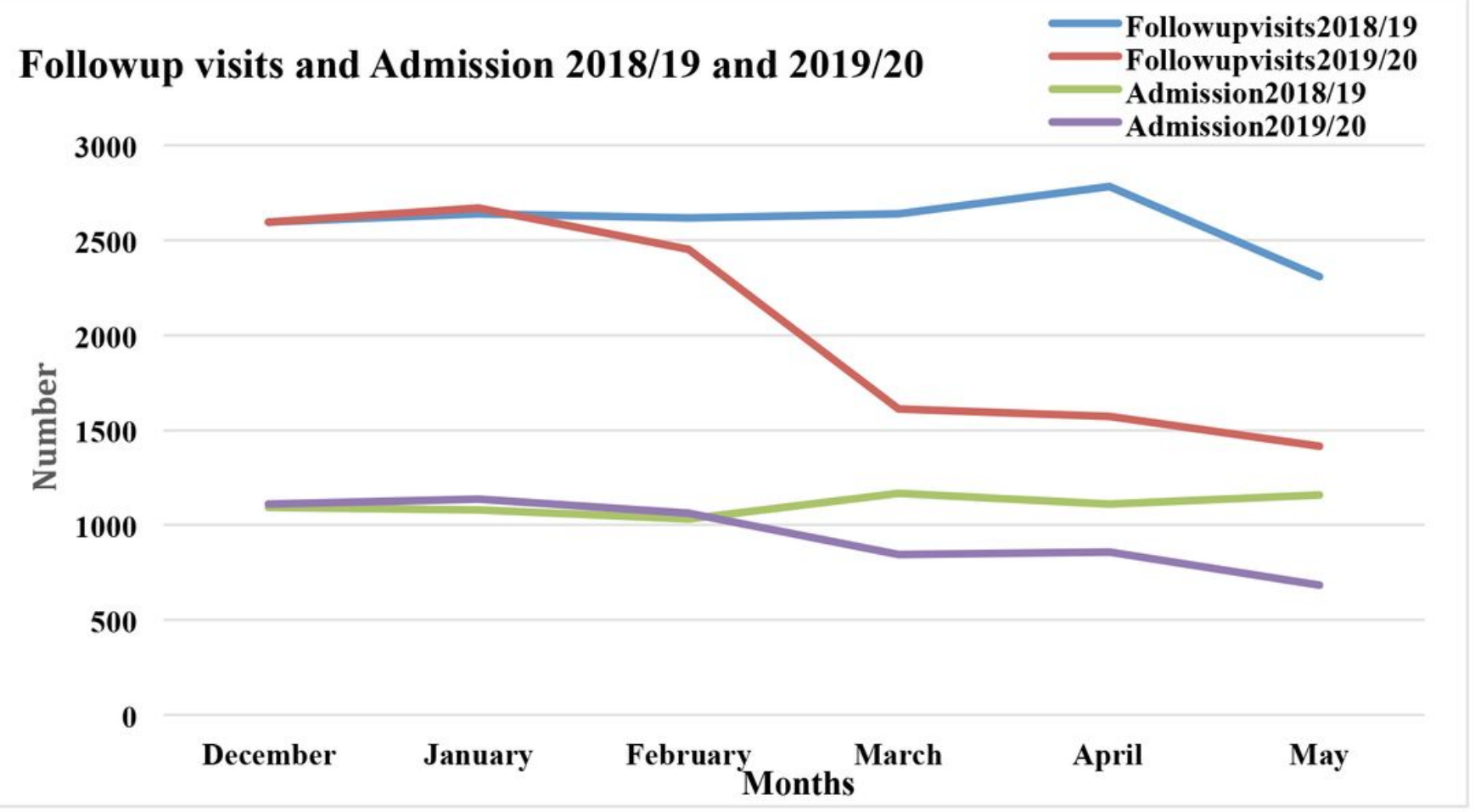

\section{Figure 2}

Trends in the number of daily follow-up visits from selected clinics by gender from December 2019 to May 2020 Figure 3 depicted follow up clinics visits separately. In 2019/20, the number of visits at the follow up clinics decreased when compared to the same time period in 2018/19. The relative reduction in monthly follow-up visits was observed in all clinics, except endocrine and hematology- oncology clinics. 


\section{Six months attendance from follow-up clinics at TASH}

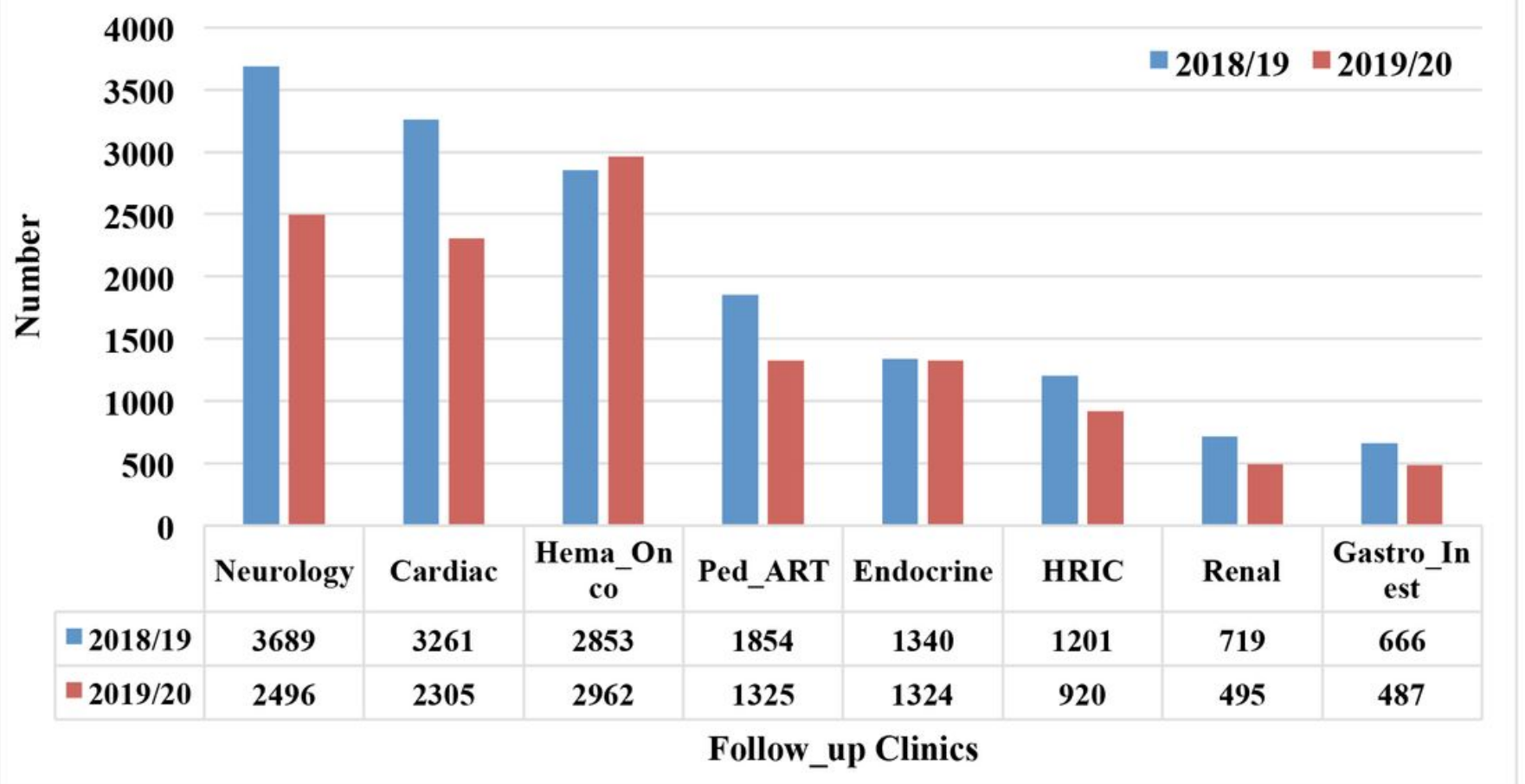

Figure 3

Monthly follow-up visits, December 2019 to May 2020 relative to equivalent period in 2018/19. The trend of admissions in the pediatric emergency between December 1st, 2019, and May 31st, 2020 is illustrated in Figure 4. The monthly report of the number of children who were admitted to the pediatrics Emergency room (ER) showed a significant drop in the month of March and there was no rebound in the month of May $(p=0.04)$. 
Pediatric ER Admission and Death 2018/19 and 2019/20

600

500

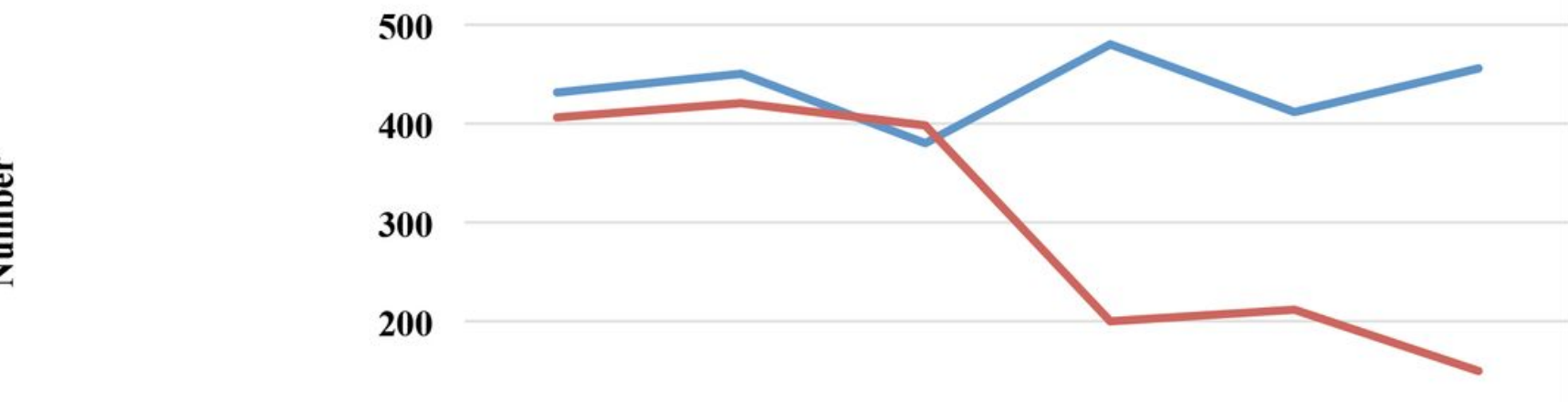

100

हั

\begin{tabular}{|c|c|c|c|c|c|c|}
\hline 0 & December & January & February & March & April & May \\
\hline ERadmission2018/19 & 431 & 450 & 380 & 480 & 412 & 456 \\
\hline ERadmission2019/20 & 406 & 421 & 398 & 200 & 212 & 150 \\
\hline
\end{tabular}

Figure 4

Pediatric ER Admission, December 2019 to May 2020 relative to equivalent period in 2018/19. Figure 5a and $5 \mathrm{~b}$ illustrate the monthly pediatrics and adult ward admissions and deaths respectively. Pediatrics ward admissions at TASH decreased since the month of February, with the highest drop observed in the month of May 2020. However the difference was not statistically significant $(p=0.34)$. Adult medical admissions did not show any difference in 2020 compared to the previous year $(P=0.12)$. 

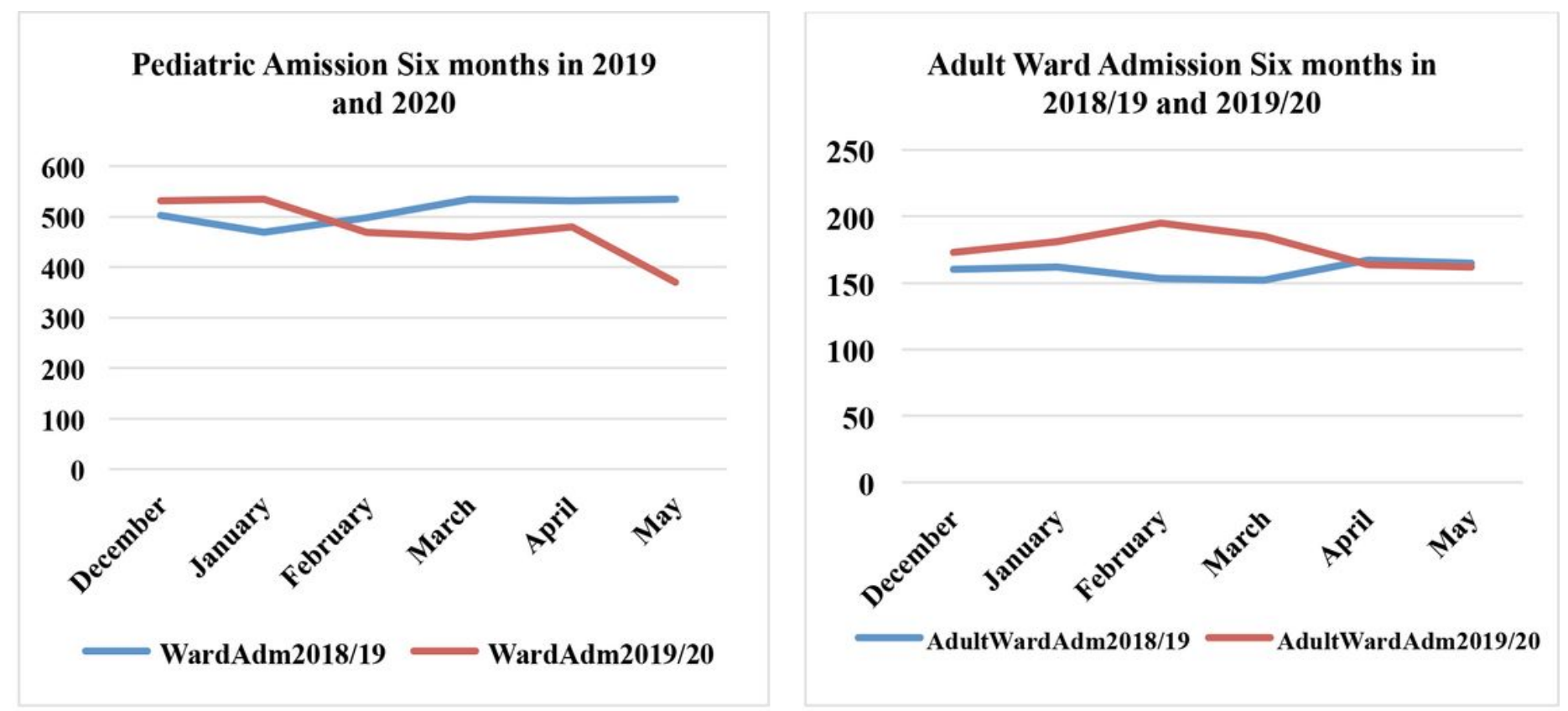

Figure 5

Figure 5a and 5b: Pediatrics and adult ward admissions, December 2019 to May 2020 relative to equivalent period in 2018/19. 